\title{
MULTI PARAMETERS EFFECT ON THERMOHYDRAULIC INSTABILITY IN NATURAL CIRCULATION BOILING WATER REACTOR DURING STARTUP
}

\author{
Muhammad Hadid SUBKI, Noriyuki WATANABE, \\ Masanori ARTOMI, Moon KI CHUNG, Hiroshige KIKURA \\ Research Laboratory for Nuclear Reactors \\ Tokyo Institute of Technology \\ 2-12-1 Ohokayama, Meguro-ku, Tokyo 152-8550, JAPAN \\ T: +81-3-5734-3063, F: +81-3-5734-2959, E: subki@2phase.nr.titech.ac.jp
}

Keywords: instability, boiling water reactors, natural-circulation, start-up

\begin{abstract}
Feasibility study on the future light water reactor has been carried out. Small- and medium-sized natural circulation boiling water reactor (BWR) has been one of the concepts. One of the indispensable topics is thermohydraulic instability during startup. Occurrence of the instability during the startup negatively affects safety, reliability and operability, as it would cause complexity in raising and maneuvering reactor power. The purpose of the study is to experimentally investigate driving mechanism of major instabilities simulated in a natural circulation experimental loop, under a predetermined range of system operating pressure and inlet subcoolings. Pressure range of 0.1 up to $0.7 \mathrm{MPa}$, input heat flux range of 0 up to $577 \mathrm{~kW} / \mathrm{m}^{2}$, and inlet subcoolings of 5,10 and $15 \mathrm{~K}$ respectively, were applied in the experiments. The objective of this paper is to offer new experimental data as the basis to propose rational startup procedure, in which various thermohydraulic instabilities can be prevented. The study clarifies that four (4) kinds of thermohydraulic instability might occur even up to a higher pressure of $0.7 \mathrm{MPa}$. The clarified sequence instabilities are as follows: (1) geysering induced by condensation accompanied by flashing, (2) oscillation induced by hydrostatic head fluctuation, (3) density wave oscillations, and (4) flashing accompanying those instabilities. The experiments confirmed that the geysering region gets narrower and suppressed with the increased system pressure. With chimneys, natural circulation can be achieved reliably and more easily. However, the flashing in the chimney cannot be avoided at low system pressure. Stable two-phase natural circulation can be established if the system pressure is increased beyond $0.7 \mathrm{MPa}$, after the high frequency density eave oscillation thoroughly suppressed. The experiments were analyzed based on frequency domain of each instability phenomenon.
\end{abstract}

